\title{
Aprendendo biologia celular por meio da construção da célula eucarionte animal
}

\author{
Learning cell biology through animal eukaryotic cell construction \\ Aprendizaje de la biología celular a través de la construcción de la célula eucariota animal
}

Recebido: 26/10/2021 | Revisado: 06/11/2021 | Aceito: 13/11/2021 | Publicado: 16/11/2021

\author{
Halis Gonçalves da Silva \\ ORCID: https://orcid.org/0000-0003-3986-4044 \\ Universidade Federal de Catalão, Brasil \\ E-mail: halis_silva@discente.ufcat.edu.br \\ Elisânia da Silva Brito Rodrigues \\ ORCID: https://orcid.org/0000-0001-8876-6876 \\ Universidade Federal de Catalão, Brasil \\ E-mail: elisania_silva@discente.ufcat.edu.br \\ Maria Rita de Cássia Campos \\ ORCID: https://orcid.org/0000-0002-4610-4353 \\ Universidade Federal de Catalão, Brasil \\ E-mail: maria_rita_campos@ufcat.edu.br
}

\begin{abstract}
Resumo
O ensino de biologia celular é importante, pois representa, além da memorização de conceitos, um passo para o interesse científico. No entanto, o entendimento de estruturas celulares e a compreensão dos eventos que ocorrem em nível microscópico é um desafio para os alunos e professores. Objetivou-se, neste trabalho, a construção de uma célula eucarionte animal pelos estudantes à medida que o conteúdo teórico fosse abordado. Para isso, foi apresentada uma situação-problema: Como tornar conceitos científicos e abstratos compreensíveis utilizando a modelagem? O estudo investigativo compreendeu dois instrumentos de coleta: um diálogo em sala de aula e a construção individual de uma célula eucariótica animal. Os alunos realizaram autoavaliação e avaliação crítica dos demais grupos. Os modelos confeccionados apresentaram formas e tamanhos variados, respeitando as características das células escolhidas. No presente trabalho, a construção de uma célula eucariótica estimulou o interesse e a curiosidade, possibilitando diferentes formas de aprendizado sobre as células eucarióticas animais. Em seus relatos, os alunos consideraram que a atividade foi prazerosa e construtiva a partir do momento em que pesquisaram sobre as partes da célula, suas estruturas e funções. Esse estudo aponta que a construção de modelos didáticos por meio de uma atividade investigativa é importante e tem como resultado uma aprendizagem significativa.
\end{abstract}

Palavras-chave: Ensino; Célula; Modelo didático 3D; Biologia.

\begin{abstract}
The teaching of cell biology is important because it represents, in addition to memorizing concepts, a step towards scientific interest. However, understanding cellular structures and events that occur at the microscopic level is a challenge for students and teachers. This work aimed to construct an animal eukaryotic cell by students as the theoretical content was approached. For this, first, a problem-situation was presented: How to make scientific and abstract concepts understandable using modeling? The investigative study comprised two data collection instruments: a classroom dialogue and the individual construction of an animal eukaryotic cell. The students performed selfassessment and critical evaluation of the other groups. The built models had different shapes and sizes, respecting the characteristics of the chosen cells. In the present work, the construction of a eukaryotic cell stimulated interest and curiosity, enabling different ways of learning about animal eukaryotic cells. In their reports, the students considered the activity was pleasurable, constructive from the moment they researched the parts of the cell, its structures and functions. This study indicates that the construction of didactic models through investigative activity is important and results in significant learning.
\end{abstract}

Keywords: Teaching; Cell; 3D didactic model; Biology.

\section{Resumen}

La enseñanza de la biología celular es importante pues representa además de la memorización de conceptos, un paso para el interés científico. Sin embargo, comprender las estructuras celulares y comprender los eventos que ocurren a nivel microscópico es un desafío para estudiantes y maestros. El objetivo de este trabajo fue la construcción de una célula eucariota animal por parte de los estudiantes a medida que se abordaba el contenido teórico. Por eso, fue presentado una situación-problema: ¿Cómo hacer comprensibles los conceptos científicos y abstractos usando modelos? El estudio de investigación comprendió dos instrumentos de recolección de datos: un diálogo en el aula y la construcción individual de una célula eucariota animal. Los estudiantes realizaron una autoevaluación y evaluación crítica del resto de trabajos realizados. Los modelos confeccionados presentaron formas y tamaños variados, 
respetando las características de las células escogidas. En el presente trabajo se observó que la construcción de una célula eucariota estimuló el interés y la curiosidad, posibilitando formas diferentes de aprendizaje sobre célula eucariótica animal. En sus informes los alumnos consideraron que la actividad fue agradable, constructiva desde el momento en que buscaron, a través de la investigación, conocimientos relacionados con las partes de la célula, sus estructuras y funciones. Este estudio señala que la construcción de modelos didácticos a través de la actividad investigativa es importante y tiene como resultado un aprendizaje significativo.

Palabras clave: Modelo didáctico 3D; Célula; Enseñanza; Biología.

\section{Introdução}

A Biologia Celular é uma das disciplinas básicas para o entendimento da relação entre a morfologia e a composição da célula. O ensino desse componente curricular tem sua importância, pois, representa além da memorização de conceitos, um direcionamento para o interesse científico. No entanto, o ensino e a aprendizagem deste conteúdo constituem uma busca por respostas pela comunidade escolar nos diferentes níveis de ensino (Nigro et al., 2007). A investigação dessa problemática é acentuada pelas dificuldades encontradas por professores e alunos no entendimento da linguagem empregada na biologia celular e que parecem distantes da realidade desses. Nesse contexto, o uso de métodos alternativos e didáticos de ensino, que propiciem ao estudante um aprendizado mais interativo, apresenta-se como alternativa para o ensino, uma vez que propicia a assimilação dos conteúdos pela curiosidade inerente a cada indivíduo (França \& Sovierzoski, 2018).

O conteúdo de biologia celular exige um aprofundamento na compreensão por se tratar de conceitos, hipóteses e fenômenos que necessitam de entendimento por meio de representações simbólicas em níveis macro e microscópicos (Gregório et al., 2016). Assim, discentes em diferentes níveis de escolaridade, têm dificuldade de compreender as reais dimensões das estruturas biológicas, o que contribui para a dificuldade de relacionar conceitos científicos com o cotidiano. Neste sentido, cabe ao professor viabilizar estratégias que tornem o estudo deste componente acessível e de melhor compreensão, tendo em vista a dificuldade de se explicar exclusivamente em palavras os processos intra e extracelulares (Junqueira \& Carneiro, 2012).

No cenário atual é possível observar maior adesão dos professores ao uso de materiais que facilitem o ensino e que contribuam ativamente na elaboração de produtos de apoio, principalmente considerando o ensino remoto. A pandemia da Covid-19 provocou nos professores a necessidade, além da adaptação na utilização de plataformas digitais, de uma busca por materiais alternativos para motivar o ensino (Freitas \& Santos, 2021, Silva et al., 2021, Oliveira et al., 2021). Esta necessidade de adaptação às mudanças está diretamente relacionada a uma geração de estudantes no mundo contemporâneo que já não assume uma postura passiva.

O ensino de conteúdos biológicos, por meio de modelos didáticos, possui grande relevância, uma vez que o discente passa a ser o centro da aprendizagem, construindo o conhecimento sobre o objeto de estudo, contrapondo-se ao ensino tradicional, no qual o estudante apenas obtém uma variedade de informações teóricas sobre o assunto. Nesse sentido, a elaboração e a utilização dos recursos educativos tridimensionais favorecem o aprendizado de estruturas microscópicas de forma ampliada permitindo assim a observação, exploração e manipulação do material (Wommer, Michelloti \& Loreto, 2019).

Os modelos possibilitam que o aluno construa o seu conhecimento e não apenas receba as informações teóricas, relacione as partes com o todo, tornando as aulas mais dinâmicas e produtivas, facilitando o aprendizado (Matos et al., 2009; Orlando et al., 2009). Além disso, vários trabalhos relatam os benefícios decorrentes da utilização de modelos didáticos, principalmente os tridimensionais, no processo de ensino-aprendizagem (França \& Sovierzoski, 2018; Dantos, Oleques \& Boelter et al., 2018; Gonçalves, 2021; Souza et al., 2021; Oliveira et al., 2021).

A modelização vem sendo assinalada como uma escolha promissora no ensino de ciências (Dantos et al, 2018). No entanto, é importante ressaltar que, apenas o uso de materiais tridimensionais não garante uma inovação no ensino. É necessário despertar o interesse do aluno pelo potencial do material educativo, de forma a ampliar a capacidade de observação 
e aproximação com a realidade deste aluno. Desta forma, o presente trabalho teve como objetivo a elaboração de uma célula eucariótica pelos alunos de forma a fixar o conteúdo de biologia celular à medida que o conteúdo teórico fosse abordado.

\section{Metodologia}

Este trabalho apresenta uma pesquisa de abordagem qualitativa, por considerar as especificidades do processo de aquisição de conhecimentos por parte dos alunos/futuros professores no processo de construção de uma célula eucarionte animal e, por tentar entender e descrever o que acontece com os alunos diante de uma situação-problema (Lüdke \& André, 1986) Creswell (2010, p. 209) denomina "interpretativa", onde "os pesquisadores fazem uma interpretação do que enxergam, ouvem e entendem".

O estudo teve início com a apresentação de uma situação-problema que teria que ser resolvida a partir de discussões em sala de aula. Tais discussões ocorreram entre professor discente, discente monitor e discente-discente. A situação-problema foi a seguinte: Como tornar conceitos científicos e abstratos compreensíveis utilizando a modelagem? A partir desse questionamento surgiu a possibilidade de construir uma célula eucariótica animal à medida que os conceitos teóricos fossem apresentados. Como a cada conteúdo teórico haveria construção de uma parte da célula, seu tamanho deveria ser compatível com as idas e vindas de casa assim como com o material a ser utilizado.

As atividades foram desenvolvidas por 44 alunos do $1^{\circ}$ Período do Curso de Licenciatura em Ciências Biológicas da Universidade Federal de Catalão, durante a disciplina de Biologia Celular. Essa disciplina é a primeira a abordar conceitos de célula no curso e possui como objetivo permitir ao aluno o desenvolvimento de uma visão integrada sobre estrutura e função celular. As aulas são divididas em teóricas dialogadas, ilustradas por micrografias, ultramicrografias e em práticas no laboratório envolvendo os aspectos estruturais e ultraestruturais de células.

\section{Etapas da elaboração da célula}

As células foram sendo construídas à medida que o conteúdo era explorado em aulas teóricas que antecedem às práticas. Para a elaboração destas células, durante um semestre, foram necessários domínio do conteúdo e acompanhamento de monitores e da professora regente. Para o domínio do conteúdo era necessário que o aluno buscasse apoio em um referencial teórico, principalmente para escolha da imagem a ser explorada. No primeiro mês, os alunos escolheram a metodologia e os referenciais que fundamentaram (conceitual e pedagogicamente) o modelo a ser produzido e o material a ser utilizado. A confecção do modelo ocorreu no segundo e terceiro mês, neste período o aluno utilizou o horário após o término das práticas para expor suas dúvidas e, também seu material em construção.

Para a etapa da construção seguiram-se as seguintes etapas:
A) Elaboração da estrutura Membrana
B) Produção da estrutura Núcleo
C) Inserção do Citoesqueleto
D) Inserção de Organelas

\section{Análise dos dados}

Para avaliação foram utilizados dois instrumentos de coleta de dados: um diálogo em sala de aula e a construção individual de uma célula eucariótica animal. Para a análise dos dados sobre as impressões dos alunos em relação ao trabalho foram utilizadas apenas as respostas de forma representativa do grupo após a autoavaliação e avaliação crítica dos outros trabalhos desenvolvidos. No momento dos relatos foram feitas anotações dos pontos mais discutidos e utilizou-se a análise 
textual discursiva (ATD) proposta por Moraes, Galiazzi e Ramos (2012). Todos os critérios de avaliação foram apresentados aos alunos. Cabe ressaltar que, além da apresentação do recurso em sala de aula e da justificação em relação ao espaço educativo, houve a etapa em que se preocupou em desenvolver a sua avaliação, ao menos preliminarmente (isto é, a partir do potencial aparente dos materiais produzidos, sem considerar sua aplicação propriamente dita). Os critérios da avaliação do modelo desenvolvido foram: aplicabilidade, conceitos abordados e apresentação oral do modelo.

\section{Resultados e Discussão}

A partir da proposta de elaboração do recurso didático e da explicitação sobre o conhecimento biológico, os discentes iniciaram pesquisas a respeito de cada estrutura que compõe a célula eucariótica animal, além de observar as diferenças existentes em função da localização de cada célula. As células foram montadas, na maioria, em placas de mdf medindo $20 \mathrm{X} 20 \mathrm{~cm}$ sendo o biscuit e a tinta artesanal os materiais mais utilizados. A massa de biscuit foi escolhida por ser de fácil manuseio, ter boa durabilidade e não alterar o modelo. Alguns alunos, no início, utilizaram massa de modelar, mas, os modelos foram desmanchando e, os mesmos alteraram para o uso de biscuit. Como o início da confecção ocorria no laboratório houve troca de materiais e ideias. Nesse momento de diálogo entre estudantes, entre estudantes e monitores e entre estudantes e professor, a maior dificuldade observada foi sobre qual célula escolher. Após essa decisão os resultados mostraram que os modelos confeccionados apresentaram formas e tamanhos variados, respeitando as características das células escolhidas.

A confecção da estrutura membrana foi baseada no modelo do mosaico fluido, mostrando a bicamada lipídica com proteínas e carboidratos ligados a proteínas ou a lipídios. Nesse momento houve uma preocupação em destacar a assimetria da membrana plasmática. Para isso, os alunos usaram cores diferentes para representar os lipídios. Outro ponto levantado foi em relação à função das proteínas. As proteínas foram representadas considerando o transporte do meio extracelular para o meio intracelular.

O citoesqueleto foi representado com seus componentes, na maioria dos modelos como uma malha entrelaçada posicionada ao longo do citoplasma. O objetivo de alguns alunos foi mostrar filamentos de actina, filamentos intermediários e microtúbulos associados e não representados, como nas imagens da maioria dos livros didáticos, em par como centríolos.

O núcleo foi posicionado, na maioria dos modelos, como estrutura quase que central ou basal, mas sempre proeminente. Vale destacar que houve um cuidado em conectar o citoesqueleto ao complexo de proteínas da membrana nuclear aqui representado pela proteína Kash (também chamada nesprina) (Junqueira \& Carneiro, 2012). No entanto, observou-se que os alunos mantiveram o conceito da morfologia nuclear apresentando um núcleo circular com recorte mostrando nucléolo e cromatina como descrito nos livros didáticos.

As organelas foram dispostas sobre o citoesqueleto e distribuídas de acordo com a localização da célula. Houve uma preocupação com as cores e tamanho das organelas. Neste trabalho os alunos repetiram imagens de organelas observadas no material didático consultado.

Inicialmente, os alunos desacreditaram da atividade como instrumento de aprendizagem e, tiveram dúvidas quanto ao material que deveria ser utilizado. Os próprios alunos começaram a informar ao colega dos erros e acertos no modelo. Essa troca de ideias foi favorável ao processo de elaboração do modelo. A construção da membrana gerou discussão sobre fluidez, assimetria e transporte transmembrana quando posicionaram os lipídios e as proteínas. Nesse momento buscaram respostas conceituais nos livros de apoio. A cooperação no aprendizado, através do uso de modelos tridimensionais foi notada como positiva em outros estudos: ensino de entomologia (Matos, 2009), modelos didáticos manuseáveis para inclusão (Michelotti \& Loreto, 2019), modelos em biscuit como ferramenta para ensino de embriologia (Paula et al., 2017), simulação da resposta imune celular mediada por linfócitos T CD8+ (Gonçalves, 2021) e modelos didáticos de DNA (Silva et al., 2021). Nesse estudo foi notável a discussão e a necessidade do apoio pedagógico e dos livros, pois transcrever para um modelo uma imagem 
não foi uma tarefa considerada fácil pelo grupo de alunos envolvidos. Duso (2013) destaca que o uso da modelização visa ampliar a reflexão, o debate e a participação ativa dos estudantes no processo de sua aprendizagem. Além disso, outros autores relatam sobre a importância da relação entre teoria e prática e o potencial desse tipo de interação na aprendizagem (Campos $e t$ al., 2003, Carneiro et al., 2016; Paula et al., 2017).

No momento de inserir o citoesqueleto os alunos iniciaram uma nova discussão. O citoesqueleto devido à composição, tamanho e posição e, mesmo com a utilização da bibliografia com representações, os alunos apresentaram dificuldades na hora de interpretar e aplicar suas observações. Conhecendo a composição e função tiveram dúvidas para posicionar os microtúbulos e os filamentos de actina. A visualização em 3D de uma estrutura formada por componentes proteicos gerou desconforto nos alunos. Isso é explicado em parte devido a certo grau de passividade dos alunos, atuando como expectadores (Pontes, Rego \& Junior, 2006; Cezar et al., 2010) e a dificuldade de estabelecer uma conexão com o mundo ao seu redor, consequência de um aprendizado de memorização que resultou na falsa impressão de aprendizado (Ferreira \& Almeida, 2013).

Na elaboração do núcleo e disposição das organelas surgiram menos dúvidas mostrando que os alunos foram capazes, na maioria, de ir construindo junto com a célula seu aprendizado. Esse fato demonstra também que a disposição das organelas constituía parte do conhecimento retido em outra situação. A partir do momento que se sentiu estimulado, o interesse pela aprendizagem passou a ser prazeroso para os alunos. Camargo e Rosa (2013) enfatizam que a aplicação da metodologia lúdica contribui para um ensino mais prazeroso e interessante, pois no decorrer da sua aplicação, os alunos sentem-se empenhados e motivados a realizá-la, tanto em equipe quanto individualmente.

$\mathrm{Na}$ apresentação os alunos explicaram como foi confeccionada a célula, localização, importância e, em alguns casos, as ocorrências de doenças pelo mau funcionamento. Além disso, deram ênfase na aplicabilidade da prática como um todo. Notou-se que, quando os alunos não buscaram referência bibliográfica ou não tiveram troca de experiências com os colegas, a apresentação e a discussão foram comprometidas. Para confeccionar as células os estudantes do entendimento do conteúdo, senso de responsabilidade e acompanhamento de todo o processo como já apontado por Soares et al. (2021).

O uso de modelos didáticos, como relatado por Silva et al. (2021), ajudam na compreensão e no aprendizado de processos biológicos, além de estimular a curiosidade e participação. Isso decorre do fato de que o simples manuseio das peças durante a atividade constitui uma forma de interação do aluno com o objeto de conhecimento, o que se torna uma ação prazerosa para o estudante (Matos, 2009). Segundo Roque et al. (2020) a elaboração de modelos pelos estudantes viabiliza o compartilhamento de experiências e ideias direcionados à aproximação da teoria ao contexto de vida do estudante, possibilitando a realização de aulas mais atrativas do que quando abordadas de forma predominantemente teórica. Uma parte das células construídas pelos alunos está representada na Figura 1. 
Figura 1 - Célula eucarionte animal, construída individualmente pelos alunos na disciplina de biologia celular
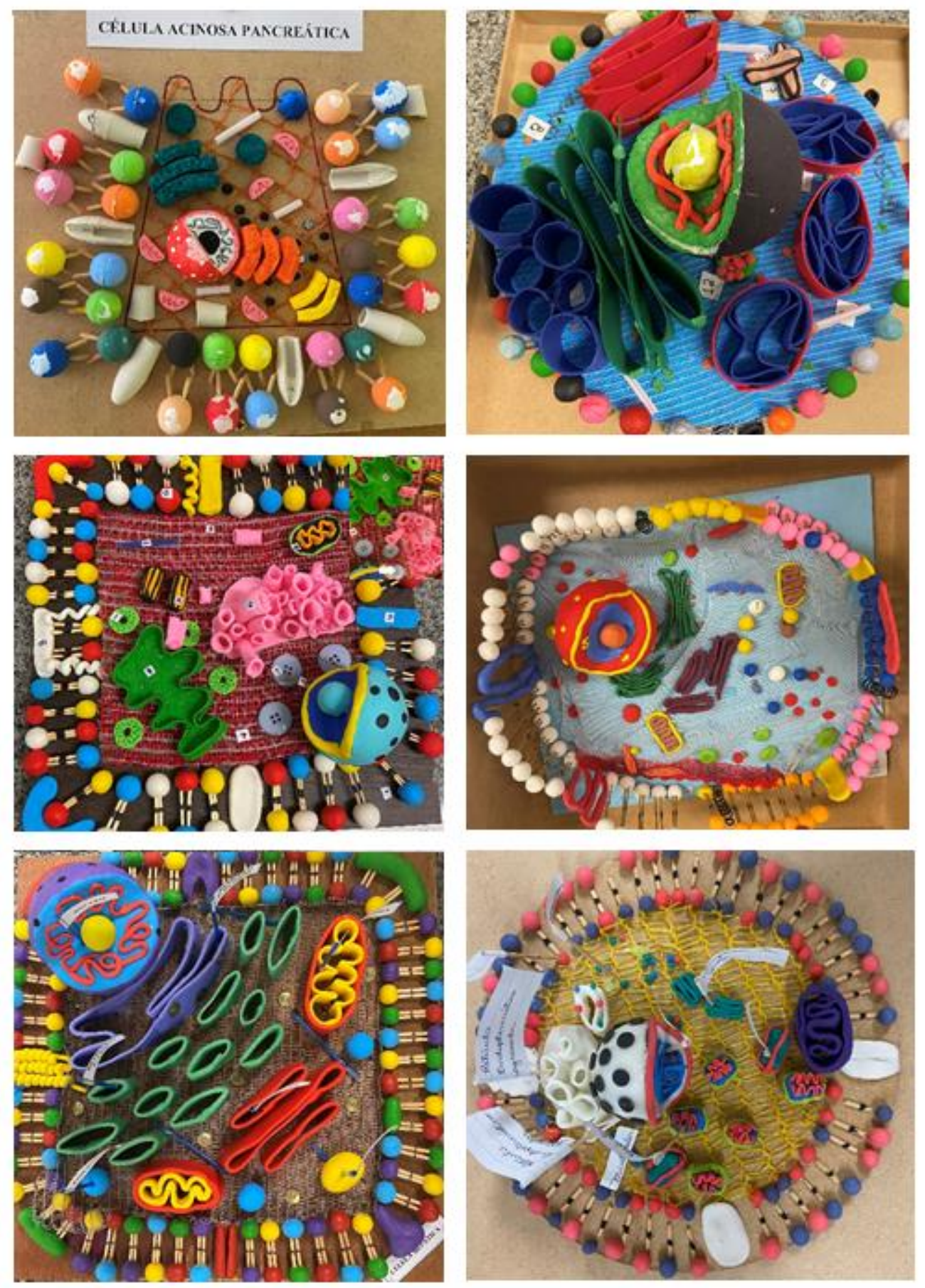

Fonte: Autores.

Uma das limitações no uso de modelos didáticos em três dimensões apontada por Krasilchik (2004) é o fato de uma simplificação do objeto real. Assim, é necessário que os estudantes estejam envolvidos na sua produção para que ocorra a aprendizagem, onde o aluno poderá compreender as limitações das representações e saber interpretar suas simplificações. Neste trabalho, como já apontado por Dantos et al. (2018), os modelos construídos proporcionaram uma “saber fazer”, onde ao pesquisar os alunos se comprometeram em pensar, criar e produzir. Por fim, os alunos consideraram que esta é uma boa metodologia didática que deve ser utilizada em sala de aula como ferramenta complementar à aula expositiva. 


\section{Considerações Finais}

A associação de conteúdos teóricos de biologia celular com o cotidiano do estudante não é uma tarefa fácil para o educador. A proposta apresentada aqui teve o objetivo de instigar o interesse dos educandos e reforçar o aprendizado de forma a preencher as lacunas que persistiram após explanação teórica. $\mathrm{O}$ ato de construir estimulou o interesse e a curiosidade, possibilitando formas diferentes de aprendizado sobre célula eucarionte animal, além de favorecer a aquisição e retenção de conhecimentos.

Outro ponto observado neste trabalho foi a possibilidade de obtenção de um material educacional sem envolver uma tecnologia moderna e que ao mesmo tempo estimulou o aprendizado de maneira prazerosa com visualização concreta do conceito estudado na teoria. $\mathrm{O}$ fato de os alunos irem construindo aos poucos a célula exigiu que os mesmos estivessem atentos aos apontamentos teóricos. Essa metodologia "do ir construindo junto" tornou-se uma maneira de colocar o aluno como agente da ação e nesse estudo foi favorável ao aprendizado. Nesse sentido, sugere-se que atividades práticas, tendo o aluno como o centro do aprendizado sejam contempladas em outros componentes curriculares.

\section{Referências}

Campos, L. M. L., Bortolotto, T. M. \& Felício, A. K. C. (2003). A Produção de jogos didáticos para o ensino de Ciências e Biologia: uma proposta para favorecer a aprendizagem. Caderno dos Núcleos de Ensino, 35-48.

Carneiro, C. C. M., Cortês, B. M., Borges, P. V., \& Campos, M. R. C. (2016). Elaboração de jogos educativos para o ensino de célula eucarionte. Arquivos do Mudi, 20 (1), 51-63. https://periodicos.uem.br/ojs/index.php/ArqMudi/article/view/31992/pdf

Camargo, P. S. A. S. \& Rosa, E. C. A ludicidade como estratégia pedagógica na educação de jovens e adultos - EJA (2013). Mimesis, 34 (2), 219-232. https://secure.unisagrado.edu.br/static/biblioteca/mimesis/mimesis_v34_n2_2013_art_05.pdf

Cezar, P. H. N., Guimarães, F. T., Gomes, A. P., Rôças, G. \& Siqueira-Batista, R. (2010). Transição paradigmática na educação médica: um olhar construtivista dirigido à aprendizagem baseada em problemas. Revista Brasileira de Educação Médica, 34 (2), 298-303. https://doi.org/10.1590/S010055022010000200015 .

Creswell, J. W. W. (2010) Projeto de pesquisa: métodos qualitativo, quantitativo e misto. (2a ed.). Bookman.

Dantos, D. C., Oleques, L. C. \& Boelter, R.A. (2018). A importância na produção de material didático pedagógico para o ensino de biologia celular. Revista de Educación en Biología - Número Extraordinario, 625-630. http://congresos.adbia.org.ar/index.php/congresos/article/view/416/360.

Duso, L., Clement, L., Pereira, P. B., de Pinho Alves Filho, J. (2013). Modelização: uma possibilidade didática no ensino de biologia. Ensaio Pesquisa em Educação em Ciências, 15 (2), 29-44. https://www.scielo.br/j/epec/a/WkG47GMnWR7jL8FqsxMNdFv/?format=pdf\&lang=pt

Ferreira, J. C. \& Almeida, S. A. (2013). O pensar e o fazer modelos didáticos por alunos de licenciatura em biologia. Atas do IX Encontro Nacional de Pesquisa em Educação em Ciências - IX ENPEC Águas de Lindóia, SP $\quad$ - $10 \quad$ a $14 \quad$ de Novembro de 2013. http://abrapecnet.org.br/atas_enpec/ixenpec/atas/resumos/R0197-1.pdf.

França, J. P. R. \& Sovierzoski, H. H. Uso de modelo didático como ferramenta de ensino em citologia (2018). R. bras. Ens. Ci. Tecnol., 11 (2), 651-665. https://periodicos.utfpr.edu.br/rbect/article/view/8474/pdf

Freitas, F. A. M. \& Santos, E. S. (2021). Os entraves do ensino remoto para formação acadêmica no curso de ciências - biologia e química no IEAA/UFAM. Revista Prática Docente, 6 (1). http://doi.org/10.23926/RPD.2021.v6.n1.e18.id1020.

Gonçalves, T. M. (2021). A guerra imunológica das células contra os patógenos: a proposta de um modelo didático tridimensional de baixo custo para simulação da resposta imune celular mediada por linfócitos $\mathrm{T}$ CD8+. Brazilian Journal of Development, 7 (1), 4854-4860. https://www.brazilianjournals.com/index.php/BRJD/article/view/23099/pdf

Gregório, E. A., Oliveira, L. G. \& Matos, S. A. (2016). Uso de simuladores como ferramenta no ensino de conceitos abstratos de biologia: uma proposição investigativa para o ensino de síntese proteica. Experiências em Ensino de Ciências, 11 (1), 101-125. https://if.ufmt.br/eenci/artigos/Artigo_ID303/v11_n1_a2016.pdf

Junqueira, L. C. \& Carneiro, J. (Eds) (2012). Biologia celular e molecular (9a ed). Guanabara Koogan.

Krasilchik, M. (2004). Prática de Ensino de Biologia (4a ed). Edusp.

Lüdke, M. \& André, M. E. D. A. Pesquisa em educação: abordagens qualitativas. EPU, 1986.

Matos, C. H. C., Oliveira, C. R. F., Santos, M. P. F. \& Ferraz, C. S. (2009). Utilização de Modelos Didáticos no Ensino de Entomologia. Revista de Biologia e Ciências da Terra, 9 (1),19-23. 
Michelotti, A., \& Loreto, E. L. da S. (2019). Utilização de modelos didáticos tateáveis como metodologia para o ensino de biologia celular em turmas inclusivas com deficientes visuais. Revista Contexto \& Amp; Educação, 34(109), 150-169. https://doi.org/10.21527/2179-1309.2019.109.150-169

Moraes, R., Galiazzi, M. C. \& Ramos, M. G. (2012). Pesquisa em sala de aula: fundamentos e pressupostos. In R. Moraes \& V. M. R. Lima (Eds.). Pesquisa em sala de aula: tendências para a educação em novos tempos, 11-20. Edipucrs.

Nigro, R. G., Campos, M. C. C.\& Dessen, E. M. B. (2007). A célula vai até a escola. Genética na escola, 2 (2), 4-10.

Oliveira, A. A. R., Cardoso, D. F. \& Lopes-Mattos, K. L. B. (2021). Vídeoaula sobre órgãos vegetativos como recurso didático no ensino remoto. v. 1 n. 1 (2021): Anais Educação em Foco: IFSULDEMINAS. https://educacaoemfoco.ifsuldeminas.edu.br/index.php/anais/article/view/156/114

Orlando, T., C., Lima, A. R. Silva, A. M., Fuzissaki, C. N., Ramos, C. L., Machado, D., Fernandes, F. F., Lorenzi, J. C., Lima, M. A., Gardim, S., Barbosa, V. C.\& Tréz, T. A. (2009). Planejamento, montagem e aplicação de modelos didáticos para abordagem de biologia celular e molecular no ensino médio por graduandos de ciências biológicas. Revista Brasileira de Ensino em Bioquímica e Biologia Molecular, 1, A1-A17. http://bioquimica.org.br/revista/ojs/index.php/REB/article/view/33

Paula, L., Reis, M, Rodovalho, A. R. S., Guimarães, G. S. \& Campos, M. R. C. (2007). Modelos em biscuit: uma ferramenta para o ensino de embriologia. Congresso nacional de ensino de ciências e formação de professores. UFG-Regional Catalão. http://cecifop.sistemasph.com.br/in dex.php/cecifop/CECIFOP2017/paper/viewFile/149/273

Pontes, A. L., Rego, S. \& Júnior, A. G. S. (2006). Saber e prática docente na transformação do ensino médico. Revista Brasileira de Educação Médica, 30 (2), 66-75. https://doi.org/10.1590/S0100-55022006000200009

Roque, A. A., Will, N. C. \& Caetano, L. G. (2020). On the path of gene expression: a pedagogical proposal for teaching Biology. Research, Society and Development, 9 (7), e906975090. https://doi.org/10.33448/rsd-v9i7.5090.

Soares, W. S., Barbosa, M. L. de O. \& Silva, J. R. F. (2021). The use of artistic expressions in Cell Biology teaching: A proposal combining active methodologies and interdisciplinary. Research, Society and Development, 10(6), e26810615779. https://doi.org/10.33448/rsd-v10i6.15779.

Silva, J. S. Oliveira, N. C. R., Sousa, F. S. Silva Neto, C. Q., Saraiva, E. S. Brito, M. V., Sá, G. H., \& Amorim, L. V. (2021). Modelos didáticos de DNA no ensino de genética: experiência com estudantes do ensino médio em uma escola pública do Piauí. Research, Society and Development, $10(2)$, e39610212005. https://doi.org/10.33448/rsd-v10i2.12005

Silva, D. dos S., Andrade, L. A. P., \& Santos, S. M. P. dos. (2020). Teaching alternatives in pandemic times. Research, Society and Development, 9(9), e424997177. https://doi.org/10.33448/rsd-v9i9.7177

Souza, I., R. de, Gonçalves, N. M. N., Pacheco, A. C. L., \& Abreu, M. C. de. (2021). Modelos didáticos no ensino de Botânica. Research, Society and Development, 10(5), e8410514559. https://doi.org/10.33448/rsd-v10i5.14559

Wommer, F. G. B., Michelloti, A. \& Loreto, E. L. S. (2019). Proposta didática para o ensino de biologia celular no ensino fundamental: a história da ciência, experimentação e inclusão. Br. J. Ed., Tech. Soc., 12 (2), 190-197. http://dx.doi.org/10.14571/brajets.v12.n2 